agement of malignant pleural effusion. Thoracoscopic inspection of the pleural space provides optimal conditions for effective pleurodesis by facilitating a dry pleural cavity and may be more important, with regard to success, than the choice of sclerosant. Nevertheless his experience with talc is most interesting, and we agree that further data in the form of a prospective randomised trial are required to clarify management which remains largely a matter of personal experience and reflects local expertise.

PT REID

The London Chest Hospital, Bonner Road

London E2 9fX, UK \section{for malignant pleural effusions}

Corynebacterium parvum

I have read the article by Dr AG Villanueva et al (January 1994;49:23-5) on tetracycline pleurodesis for malignant pleural effusions. Tube thoracostomy drainage before instillation of tetracycline is necessary to achieve successful pleurodesis, and the authors found that short term drainage was as effective as long term drainage. Since insertion of a drainage tube is uncomfortable, the use of a sclerosing agent which can be injected into the pleural cavity without an intercostal tube is preferable. Corynebacterium parvum (CBP), unlike other sclerosing agents, has this feature. In fact, in the study by Leahy et al treatment with CBP was as effective as tetracycline injected via an intercostal tube.

I wish to report results on 28 consecutive patients treated with intrapleural CBP (Coparvax, Wellcome Foundation, London, UK) without intercostal tube drainage. Four patients were not evaluable as they died within one month. A complete response (total resolution of pleural effusion after a maximum of three injections of CBP) was seen in 22 of the remaining 24 patients. The side effects were fever (in $50 \%$ of patients) usually lasting 2-3 days, and mild or moderate chest pain (32\% of patients), both of which were effectively controlled with paracetamol or nonsteroidal anti-inflammatory drugs.

These data confirm that instillation of CBP without intercostal tube drainage is an effective, simple, and well tolerated method of controlling malignant pleural effusions. Our patients had a longer survival time (mean $7 \cdot 7$ months) than that reported by Villanueva $e t$ $a l$, and three are still alive with survival times of $11 \cdot 3,9.9$, and 5.1 months. Our results are also superior to those of patients treated with talc $(1.9$ months in patients with low pleural fluid glucose levels and low $\mathrm{pH}$ and 5.7 months in patients with high glucose and high $\mathrm{pH}$ levels), ${ }^{2}$ and to those treated with mustine (3.9 months). ${ }^{3}$ This fact is emphasised by other authors ${ }^{34}$ and suggests that CBP may be acting, not only as a sclerosant, but also as an immunostimulant.

Unfortunately, CBP has been discontinued by the Wellcome Foundation, as has injectable tetracycline. In Italy injectable tetracycline, doxycycline, minocycline, and rolitetracycline are not available. The treatment of malignant pleural effusions therefore currently requires more expensive agents or more invasive methods.

\section{FORESTI}

Via Kennedy 32, 20097 San Donato Milanese, Milan,

1 Leahy BC, Honeybourne D, Brear SG, Carrol KB, Thatcher N, Stretton TB. Treatment of malignant pleural effusions with intrapleural Corynebacterium parvum or tetracycline. Eur $\mathcal{F}$ Respir Dis 1985;66:50-4.

2 Sanchez-Armengol A, Rodriguez-Panadero F. Survival and talc pleurodesis in metastatic pleural carcinoma revisited. Report of 125 cases. Chest 1993;104:1482-5.

3 McLeod DT, Calverley PMA, Millar JW, Horne NW. Further experience of Corynebacterium parvum in malignant pleural effusion. Thorax 1985;40:515-18.

4 Felletti R, Ravazzoni C. Intrapleural Corynebacterium parvum for malignant pleural effusions. Thorax 1983;38:22-4.

\section{BOOK NOTICE}

Diseases of Occupations. 8th Edition. PAB Raffle, PH Adams, PJ Baxter, WR Lee. (Pp 804; £145.00). London: Edward Arnold, 1994. 0340551739.

Most British chest physicians also practise general medicine, and all will have passed the MRCP. At one time Hunter's Diseases of Occupations was essential reading for those taking the examination, not least because Donald Hunter was a notoriously idiosyncratic examiner. The original classic textbook in its later editions lost much of its value except as an historical reference, but this 8th edition has been completely rewritten breaking at last with the original format but honouring the original purpose "to review with emphasis on its clinical aspects the problem of disease in relation to occupation". This task inevitably requires a team of contributors, and the editors have selected a strong one. They have also achieved a reasonable uniformity of style and structure which makes the book easy to read and clinically informative.

The first five chapters contain information on preventive legislation, compensation, and medical report writing that is not readily available elsewhere. The rest of the book consists of descriptions of occupational diseases as seen nowadays, properly emphasising the common problems of musculoskeletal, psychological, skin, and hearing diseases that are of interest to other specialists. The chapters on occupational lung disorders are concise, clearly written and accurate, but necessarily lack the detail to be found in more specialised textbooks. The short chapter on indoor air pollution is one that many who are confused by the various "sick building" syndromes will find particularly helpful.

This is a much better book than the 7th edition, and deserves to be in all hospital and medical school libraries. All doctors training in general medicine should read it and will find it opens their eyes to previously unappreciated causes of disease and possibilities for prevention. And with the growing interest in environmental causes of disease, who knows
- it could even once again become essential reading for passing the MRCP! - AS

\section{Lung and Asthma Information Agency}

The Lung and Asthma Information Agency aims to bring together, interpret, and disseminate information about lung disease in order to increase awareness and understanding of the burden of lung disease and of its prevention and care. It is jointly supported by the National Asthma Campaign, the British Lung Foundation, and the British Thoracic Society. Since its launch at the BTS Summer Meeting in July 1992 it has concentrated on three areas: the production of factsheets, developing a comprehensive respiratory database, and providing an information service to the sponsors. So far, it has produced factsheets on asthma mortality in the elderly, pneumonia mortality in the elderly, pleural mesothelioma, sickness absence from respiratory disease, respiratory tuberculosis, lung cancer and smoking, GP prescribing of drugs for respiratory disease, RSV in children, seasonal variations in asthma, air pollution, and asthma prevalence. From 1995 further factsheets will be distributed with Thorax, the first on "Trends in hospital admissions for asthma" appearing with this issue. Multiple copies of factsheets, back copies of earlier factsheets, and further information about the Agency may be obtained from: Elizabeth Limb, The Lung and Asthma Information Agency, Dept. of Public Health Sciences, St George's Hospital Medical School, Cranmer Terrace, London SW 17 ORE. Tel: 01817255489. 